\title{
Erratum to: MRL-SCSO: Multi-agent Reinforcement Learning-Based Self-Configuration and Self- Optimization Protocol for Unattended Wireless Sensor Networks
}

\section{A. Pravin $\operatorname{Renold}^{1} \cdot$ S. Chandrakala ${ }^{2}$}

\section{Erratum to: Wireless Pers Commun DOI 10.1007/s11277-016-3729-3}

In the original publication, the variable $\mathrm{Er}$ in Eq. (5) should read $\mathrm{E}_{\mathrm{r}}$ and the three levels mentioned in the text between Eqs. (8) and (9) should have read ' $\alpha, \beta$, and $\Gamma$ ' instead of ' $\alpha$, $\beta$, and $\gamma$ ''

The online version of the original article can be found under doi:10.1007/s11277-016-3729-3.

\section{A. Pravin Renold} pravinrenold.tifac@velammal.edu.in; pravin_renold@yahoo.com

S. Chandrakala sckala@gmail.com; chandrakalas@skcet.ac.in

1 Mobile Ad-hoc and Sensor Network Lab, TIFAC-CORE in Pervasive Computing Technologies, Velammal Engineering College, Chennai, India

2 Department of Computer Science and Engineering, Sri Krishna College of Engineering and Technology, Coimbatore, India 